\title{
AVALIAÇÃO DA EFICÁCIA DA MOBILIZAÇÃO NEURAL NA FLEXIBILIDADE DOS MÚSCULOS ISQUIOTIBIAIS EM MULHERES SEDENTÁRIAS DE 19 A 22 ANOS
}

Daniel Tavares Camara ${ }^{1}$, José Henrique Piedade Cardoso ${ }^{1,2}$, Silas de Oliveira Damasceno ${ }^{1,4}$, Lucas Oliveira Klebis ${ }^{1,3}$, Elaine Aparecida Lozano da Silva ${ }^{1,3}$, Claúdia Regina Sgobbi Faria ${ }^{1}$, Maria Carolina Rodrigues Salini ${ }^{1}$, Ana Caroline Rippi Moreno ${ }^{1,2}$, Regina Celi Trindade de Camargo ${ }^{1}$.

${ }^{1}$ Universidade Estadual Paulista - UNESP, Curso de Fisioterapia, ${ }^{1,2}$ Especialização em Geriatria e Gerontologia, ${ }^{1,3}$ Residência em Geriatria e Gerontologia, 1,4 Especialização em Fisioterapia Aplicada à Neurologia. Presidente Prudente, SP.

\section{RESUMO}

Introdução: Os músculos isquiotibiais por serem biarticulares estão frequentemente sujeitos ao encurtamento devido à postura flexora adotada pelas pessoas nos dias de hoje e por longos períodos que elas passam sentadas. Objetivo: Verificar a eficácia da mobilização neural na flexibilidade dos músculos isquiotibias. Método: Estudo quantitativo com 5 mulheres, sedentárias, entre 19 e 22 anos de idade, que foram avaliadas pela goniometria através do teste do ângulo poplíteo. Em seguida, aplicou-se a manobra de mobilização neural 2 vezes por semana, durante 4 semanas, totalizando 8 sessões. Aplicou-se: mobilização deslizante e mobilização tensionante do nervo isquiático e deslizamento Slump. Após tratamento, foram reavaliadas. Resultados: Observou-se após o tratamento um aumento na média dos graus do joelho direito de $148,4^{\circ}$ para $166,2^{\circ}$ e do joelho esquerdo de $147,2^{\circ}$ para $166,8^{\circ}$. Conclusão: Concluiu-se que a mobilização neural minimiza o encurtamento neural, aumentando a flexibilidade e promovendo melhora na qualidade de vida.

Palavras-chave: Alongamento muscular, encurtamento muscular, isquiotibiais, flexibilidade, mobilização neural.

\section{EVALUATION OF EFFICIENCY OF NEURAL MOBILIZATION IN FLEXIBILITY OF HAMSTRINGS MUSCLE IN SEDENTARY WOMEN FROM 19 TO 22 YEARS OLD}

\begin{abstract}
Introduction: The hamstring muscles for being biarticular are often subject to shortening due to flexor posture adopted by people nowadays and for long periods they spend sitting. Objective: To verify the efficiency of the neural mobilization in the flexibility of hamstring muscle. Methods: Quantitative study with 5 women, sedentary, between 19 to 22 years old who were evaluated by goniometry through the test of the popliteal angle. Then applied to neural mobilization two time per week, during four weeks, totalizing eight sessions. Applied: sliding mobilization and tension mobilization of the sciatic nerve and Slump slip. After treatment they were reevaluated. Results: It was observed after treatment an increase in average degrees of the right knee of $148.4^{\circ}$ to $166.2^{\circ}$ and left knee of $147.2^{\circ}$ to $166.8^{\circ}$. Conclusion: It was found that the neural mobilization minimizes the shortening neural, increasing flexibility and promoting improvement in the quality of life. Keywords: Muscle stretching, shortening muscle, hamstrings, flexibility, neural mobilization.
\end{abstract}




\section{INTRODUÇÃO}

Atualmente, devido à influência do computador e da chamada Tecnologia da Informação (TI) no cotidiano das pessoas, elas passam a maior parte de seu tempo sentadas, consequentemente, levando uma vida sedentária, o que provoca sérias mudanças na sua estrutura muscular, de modo particular, sobre os isquiotibiais.

Os isquiotibiais são constituídos pela união dos músculos: bíceps femoral, semitendinoso e semimembranoso que atuam em conjunto e tem função de extensão do quadril e flexão do joelho ${ }^{1,2}$. Por serem extensores primários do quadril desempenham forte contração para estabilizar a pelve durante a extensão do tronco ${ }^{3}$.

Constituem, em conjunto com a musculatura posterior do tronco, a cadeia muscular responsável pela manutenção e alinhamento postural. Desvios posturais podem mudar a estrutura de um músculo, alterar sua ação e modificar a descarga de peso, tornando encurtado e enfraquecido, causando perda na flexibilidade e mobilidade.

Os isquiotibiais são músculos biarticulares e estão sujeitos ao encurtamento principalmente devido às posturas e posições adotadas nas rotinas diárias dos indivíduos adultos jovens ${ }^{4}$.

Déficits na flexibilidade desse grupo muscular podem provocar também outras alterações, como contratura dos isquiotibiais mediais e laterais resultando em uma posição de flexão de joelho. Se a contratura for extrema resultará em limitação da amplitude de movimento (ADM) de extensão do quadril e da inclinação anterior de tronco. Também poderão ocorrer alterações posturais como retroversão pélvica, retificação da coluna lombar, que alteram a marcha e provocam dores nos membros inferiores e até mesmo discrepância no comprimento destes ${ }^{5,6}$.

Todas essas alterações musculares causam comprometimento da biomecânica do movimento humano afetando também a funcionalidade principalmente das articulações da coluna lombar, quadril e joelho ${ }^{7}$.

O alongamento é o termo geral usado para descrever exercícios terapêuticos elaborados para aumentar a flexibilidade dos tecidos moles patologicamente encurtados e assim aumentar a amplitude de movimento de estruturas que se tornam hipomóveis e que estão com encurtamento adaptativo ${ }^{8}$.

Os alongamentos neurais são divididos em dois grupos: o primeiro é conhecido como oscilatório; esse coloca o nervo em tensão e adiciona movimentos oscilantes na extremidade distal do membro e o segundo é denominado brevemente mantido; que coloca o nervo em tensão máxima e o mantém por tempo determinado ${ }^{9}$.

Para comparação dos resultados usou-se a goniometria para avaliar a mobilidade articular, que se refere à medida de ângulos articulares ${ }^{10}$.

Por entender que um dos objetivos da fisioterapia é melhorar a qualidade de vida das pessoas, nesta pesquisa priorizou-se trabalhar com técnicas que auxiliam para essa melhora. Dentre essas técnicas, optou-se pela mobilização neural para beneficiar a flexibilidade muscular.

Assim, o objetivo do presente estudo foi verificar a eficácia da mobilização neural na flexibilidade dos músculos isquiotibias.

\section{MÉTODO}

Trata-se de uma pesquisa quantitativa, que usou do meio exploratório de pesquisa de campo para demonstrar a eficácia do protocolo aplicado na flexibilidade dos isquiotibiais por meio de manobra de mobilização neural.

O início da pesquisa se deu após aprovação do CEP - Comitê de Ética em Pesquisa, protocolo no 047649/2015, em maio de 2015.

A pesquisa foi composta por cinco pessoas do gênero feminino, saudáveis, sedentárias tendo entre 19 e 22 anos. Teve como critério de inclusão ser do sexo feminino, apresentar 
encurtamento bilateral de isquiotibiais, ser sedentário há no mínimo seis meses, não apresentar patologia limitante em coluna vertebral ou membros inferiores, não estar recebendo qualquer outro tratamento, concordar e assinar o Termo de Consentimento Livre e Esclarecido. Como critério de exclusão, a não disponibilidade de horário, possuir patologias osteomusculares e não estar dentro do critério de inclusão.

Foi aplicado o teste de avaliação do ângulo poplíteo, com a avaliada em decúbito dorsal sobre a maca, um membro inferior permaneceu em extensão sendo estabilizado por uma faixa elástica para evitar movimentos compensatórios. O membro inferior contralateral foi posicionado com flexão de $90^{\circ}$ de quadril, com ambos os tornozelos em posição neutra, o eixo do goniômetro foi posicionado no côndilo lateral do fêmur, o braço fixo em direção ao trocânter maior do fêmur e o braço móvel em direção ao maléolo lateral.

Em sequência, realizou-se uma extensão lenta e passiva de joelho até o momento em que as participantes relatassem dor ou desconforto, assim verificou-se o ângulo poplíteo indicado em graus pelo goniômetro $\left(\mathrm{CARCl}-0,20 \times 0,05[\mathrm{CxL}]^{\circledR}\right)$. 0 teste foi realizado bilateralmente em todas as participantes; antes e após as sessões de mobilização neural, para averiguar encurtamento e para constatar presença ou não de aumento da amplitude de movimento, respectivamente.

Após a avaliação, deram início ao protocolo de tratamento que foi realizado duas vezes por semana, durante um mês e com 20 minutos cada atendimento, totalizando oito atendimentos.

As manobras aplicadas foram: mobilização deslizante do isquiático, indivíduo confortável e relaxado em decúbito dorsal sobre a maca, coluna lombar, sacro e quadril em posição neutra e joelhos mantidos em extensão do início ao fim da técnica. O membro a ser mobilizado é elevado com o pé sendo mantido em posição neutra. Foram aplicadas oscilações entre a dorsiflexão e a posição neutra de tornozelo por 1 minuto, repetindo-as por cinco vezes com descanso de 30 segundos entre elas e posteriormente realizado no membro inferior contralateral, seguindo a mesma ordem.

Mobilização tensionante do isquiático foi realizada com o paciente em decúbito dorsal e corpo alinhado, o terapeuta iniciou a elevação do membro a ser mobilizado com o joelho em extensão até referiram dor ou até o aplicador sentir a reação de proteção, em seguida tracionouse e elevou-se o membro em flexão de quadril até onde o sintoma se manifestou, ao retornar à posição inicial a tração é liberada.

Por fim, o deslizamento Slump, estando o paciente sentado com os membros superiores cruzados atrás das costas com leve flexão lombar e torácica, joelho do membro a ser mobilizado em extensão. $O$ indivíduo realizou ativamente e de forma simultânea uma flexão cervical e flexão plantar, alternando o movimento com extensão cervical e dorsiflexão, três séries de 20 repetições, e após repetiu-se o mesmo procedimento no membro inferior oposto. No final do tratamento as participantes foram reavaliadas pelo mesmo método da avaliação.

Os resultados foram apresentados de forma descritiva e tabular, contendo média e desvio padrão para dados nominais e em percentuais para os dados numéricos. Os dados foram tabulados em ambiente Excel $^{\circledR}$, por meio de estatística simples, correlação e significância conforme os dados da amostra.

\section{RESULTADOS}

Participaram cinco mulheres com idade entre 19 e 22 anos.

A goniometria foi analisada antes e após o tratamento e observou-se aumento em graus na média da amplitude de movimento em ambos os membros em todas as participantes; o joelho direito de $148,4^{\circ}$ para $166,2^{\circ}$ e do joelho esquerdo de $147,2^{\circ}$ para $166,8^{\circ}$ (Tabela 1 ). Houve uma média de ganho no joelho direito de $12,71 \%$ e no joelho esquerdo de $14,71 \%$. 
Tabela 01. Resultado da Goniometria dos joelhos direito e esquerdo dos participantes antes e depois da aplicação da mobilização neural.

\begin{tabular}{l|rrrrr}
\hline & & \multicolumn{2}{|c|}{ Direito } & \multicolumn{2}{c}{ Esquerdo } \\
\cline { 3 - 6 } Participante & Idade & Antes & Depois & Antes & Depois \\
\hline A & 19 & 132 & 161 & 140 & 153 \\
B & 20 & 144 & 161 & 140 & 161 \\
C & 21 & 160 & 161 & 150 & 164 \\
D & 22 & 138 & 171 & 141 & 176 \\
E & 22 & 168 & 177 & 165 & 180 \\
\hline Média & 20,8 & 148,4 & 166,2 & 147,2 & 166,8 \\
\hline
\end{tabular}

\section{DISCUSSÃO}

A mobilização neural vem ganhando grandes avanços, como técnica de restauração do movimento e flexibilidade, já que restabelece a neurodinâmica e o fluxo axoplasmático, obtendo a homeostasia dos tecidos nervosos ${ }^{11}$.

Com a mobilização neural tem se observado significativo aumento de $A D M$, haja vista que a técnica vem se mostrando eficaz para a elasticidade da musculatura e das funções normais do sistema nervoso. Em comparação ao alongamento passivo, a eficácia da mobilização neural foi sentida também no ganho de ADM do quadril. Foram obtidos resultados que variaram entre $14 \mathrm{e}$ 28 graus de aumento na ADM de flexão de quadril no grupo submetido à mobilização neural ${ }^{12}$.

Quanto à flexibilidade do joelho, após a intervenção da técnica, os sujeitos da pesquisa apresentaram tendência de boa melhora da flexibilidade. O programa de mobilização neural mostrou ser eficaz no incremento da flexibilidade da cadeia muscular posterior. Na análise do ângulo de extensão do joelho, podendo-se assegurar a eficiência da técnica estudada na flexibilidade muscular ${ }^{12}$.

Com isso, ficou demonstrada acentuada melhora na flexibilidade dos músculos isquiotibiais. Estes achados assemelham-se aos da presente pesquisa, pois também foi verificado um aumento na flexibilidade dessa musculatura nos voluntários que aceitaram e participaram do teste após a aplicação da técnica de mobilização neural.

Em outro estudo, avaliou-se 10 indivíduos do sexo feminino, sedentários e neurologicamente assintomáticos, assim como neste estudo, constatou a eficiência da mobilização neural com o teste de elevação da perna estendida, sendo que o ganho médio de amplitude de movimento foi de $22,5^{\circ}$, o que mostra média superior a do presente estudo, o qual foi de $12,71^{\circ 12}$.

Um estudo realizado com 50 indivíduos que foram divididos em dois grupos, sendo 22 pacientes com comprometimento neural ao teste neurodinâmico e 28 sem comprometimento. Onde foi verificado que do grupo de indivíduos com comprometimento neural $90,47 \%$ apresentaram aumento da flexibilidade dos isquiotibiais, sendo a média de $10,09^{\circ}$. 0 grupo que não apresentou comprometimento neural teve como média $11,44^{\circ}$ distribuídos em $96,55 \%$ dos participantes deste grupo ${ }^{13}$.

Autores relatam que a mobilização neural através do alongamento dos isquiotibiais se mostrou efetiva em mulheres. Foi observado depois de aplicadas oito sessões, com cinco repetições cada uma e duração de 1 minuto. Esse protocolo resultou em melhora na ADM de flexão de quadril e apresentaram resultados para o membro inferior direito de $7,6^{\circ 6}$.

A mobilização neural e alongamento passivo foram aplicados para comparar a eficácia das mesmas na ADM de flexão de quadril. As técnicas foram executadas em 10 integrantes de ambos os sexos, que foram divididos em dois grupos. No primeiro grupo foi aplicada a mobilização neural de ciático e no grupo dois foi realizado o alongamento passivo por um minuto. Como resultado observou-se o maior aumento da ADM no grupo um (variação do ganho entre 14 a 28 graus) do 
que no grupo dois (ganho entre 10 e 18 graus), indo de encontro com o que foi constatado no presente estudo, no qual a mobilização neural resultou em bom ganho em graus $\mathrm{ADM}^{13}$.

\section{CONCLUSÃO}

Conclui-se que a técnica de mobilização neural foi eficaz no aumento da flexibilidade dos isquiotibiais em mulheres, evidenciando a técnica como uma das formas de prevenir lesões musculares.

\section{REFERÊNCIAS}

Tanaka C, Farah A. Anatomia Funcional das cadeias Musculares. 1o ed. São Paulo: Ícone, 1997.

Hamil J, Knutzen K. Bases Biomecânicas do Movimento. 1o ed. São Paulo: Manole, 1999.

Smith LK, Weiss E L, Lehmkuhl D L. Cinesiologia Clínica de Brunnstrom. 5o ed. São Paulo: Manole, 1997.

Reis FP. A Importância da Manutenção de bons níveis de flexibilidade nos trabalhadores que executam suas atividades laborais sentadas. Revista Produção - Santa Catarina, ISSN 1676 - 1901 / Vol. 3/ Núm. 3/ Setembro de 2003. DOI: http://dx.doi.org/10.14488/1676-1901.v3i3.563.

Amaro L, Haddad M, Trindade S, Ribeiro M. Reabilitação do Assoalho Pélvico - Nas Disfunções Urinárias e Anorretais. 1ำed. São Paulo: Seguimento Farma, 2005.

Santos F. Avaliação pré e pós-mobilização neural para ganho de ADM em flexão do quadril por meio do alongamento dos isquiotibiais. Trabalho de Conclusão de Curso de Santa Maria. Revista ConScientiae Saúde, vol. 7, núm. 4, pp. 487-495, 2008.

Kendal FP, McCreary EK, Provance PG. Músculos provas e funções. 4o ed. São Paulo: Manole, 1995.

Kisner C, Colby LA. Exercícios Terapêuticos Fundamentos e Técnicas. 3o ed. São Paulo: Manole, 1998.

Butler DS. Mobilização do sistema nervoso. $1^{\circ}$ ed. Barueri: Manole, 2003.

Marques AP. Manual da goniometria. 10 ed. São Paulo: Manole, 1997.

Monnerat E, Pereira, JS. A influência da técnica de mobilização neural na dor e incapacidade funcional da hérnia de disco lombar: estudo de caso. Revista terapia manual, v. 8, n. 35, Fev., 2010.

Smaniotto ICG, Fonteque MA. A Influência da Mobilização do Sistema Nervoso na Amplitude de Movimento da Flexão do Quadril. Revista Terapia Manual, v.2, n. 4, p. 154-157, 2004.

Fonteque MA, Petry CO, Salgado ASI, Pachecom TT. Estudo da eficácia da mobilização do sistema nervoso e do alongamento passivo para ganho de amplitude de movimento de flexão de quadril. IX Encontro Latino Americano de Iniciação Científica e $V$ Encontro Latino Americano de PósGraduação, Universidade do Vale do Paraíba, 2008. 